COLORECTAL CANCER

\title{
Quality in the technical performance of screening flexible sigmoidoscopy: recommendations of an international multi- society task group
}

\author{
T R Levin, F A Farraye, R E Schoen, G Hoff, W Atkin, J H Bond, S Winawer, R W Burt, D A Johnson, \\ L M Kirk, S C Litin, D K Rex
}

See end of article for

authors' affiliations

Gut 2005;54:807-813. doi: 10.1136/gut.2004.052282

Correspondence to:

Dr T R Levin, Kaiser

Permanente Division of

Research, 2000

Broadway, 2nd Floor,

Oakland, CA 94612

USA; Theodore.Levin@

kp.org

Revised version received

22 February 2005

Accepted for publication

8 March 2005

\begin{abstract}
Background: Flexible sigmoidoscopy (FS) is a complex technical procedure performed in a variety of settings, by examiners with diverse professional backgrounds, training, and experience. Potential variation in technical quality may have a profound impact on the effectiveness of FS on the early detection and prevention of colorectal cancer.

Aim: We propose a set of consensus and evidence based recommendations to assist the development of continuous quality improvement programmes around the delivery of FS for colorectal cancer screening.

Recommendations: These recommendations address the intervals between FS examinations, documentation of results, training of endoscopists, decision making around referral for colonoscopy, policies for antibiotic prophylaxis and management of anticoagulation, insertion of the FS endoscope, bowel preparation, complications, the use of non-physicians as FS endoscopists, and FS endoscope reprocessing. For each of these areas, continuous quality improvement targets are recommended, and research questions are proposed.
\end{abstract}

C olorectal cancer is the second leading cause of cancer death in the USA. ${ }^{1}$ Colorectal cancer screening performed with flexible sigmoidoscopy (FS) has been associated with reduced incidence and mortality from colorectal cancer in cohort studies, ${ }^{2}$ case control studies, ${ }^{3-7}$ and a randomised controlled trial. ${ }^{8}$ FS is performed in diverse environments, including dedicated hospital based endoscopy units, outpatient physician offices, and endoscopic ambulatory surgery centres.

FS is a complex technical procedure that requires training and experience to ensure accuracy and safety. ${ }^{9}$ The US MultiSociety Task Force on Colorectal Cancer developed these recommendations for the technical performance of FS and for continuous quality improvement in FS screening in conjunction with several international experts on the use of FS. The Task Force is comprised of representatives of the American College of Gastroenterology, the American College of Physicians-American Society of Internal Medicine, the American Gastroenterological Association, and the American Society for Gastrointestinal Endoscopy (ASGE). Investigators performing three large randomised clinical trials of FS provided additional expert opinion (prostate, lung, colorectal, and ovarian trial of the US National Cancer Institute (Robert E Schoen), ${ }^{10}{ }^{11}$ the UK Flexible Sigmoidoscopy Trial (Wendy Atkin), ${ }^{12}$ and the Norwegian Colorectal Cancer Prevention trial (Geir Hoff) ${ }^{13}{ }^{14}$ ).

The focus of these recommendations is on the quality of FS in relation to screening and prevention of colorectal cancer. Thus the recommendations do not address every diagnostic or therapeutic use of FS. These recommendations address the intervals between FS examinations, documentation of results, training of endoscopists, decision making around referral for colonoscopy, policies for antibiotic prophylaxis and management of anticoagulation, insertion of the FS endoscope, bowel preparation, complications, the use of nonphysicians as FS endoscopists, and FS endoscope reprocessing. For each of these areas, the underlying evidence base is reviewed, continuous quality improvement targets are recommended, and research questions are proposed (tables 1, 2).

The purpose of this paper is: (1) to provide evidence and consensus based standards for the performance of high quality screening FS and (2) to facilitate the development of constructive programmes in continuous quality improvement. Continuous quality improvement should be part of every FS screening programme.

We propose the following course of action for endoscopists found to have substandard performance, given the limitations of the current evidence base, understanding the danger of misjudging the results of patient selection as poor performance. Merely providing feedback on individual performance can be expected to result in significant improvement in performance, for individuals and collectively for all endoscopists involved. Endoscopists with suboptimal performance, who fail to improve after feedback of information, may require more direct intervention. The exact mechanism of this intervention has not been well studied. For these types of programmes to be successful it is crucial to explicitly state that the aim is not to punish. The responsibility for improvement of individual practitioners lies with the institution in which they practice, to provide opportunities to reach a sufficient level of proficiency by learning from other colleagues or attending formal courses. In the end, there may remain a small group of individuals unable or unwilling to take the necessary course of action to improve. The best method of dealing with these providers will have to be made on a case by case basis.

\section{METHODS}

Task Force members developed a list of major categories to be included in this paper, and a full PubMed Medline search

Abbreviations: FS, flexible sigmoidoscopy; FOBT, faecal occult blood test; TA, tubular adenoma; AA, advanced adenoma; SGNA, Society of Gastroenterology Nurses and Associates; ASGE, American Society of Gastrointestinal Endoscopists 


\section{Table 1 Continuous quality improvement targets}

(1) Completion of adequate follow up colonoscopy on more than $90 \%$ of patients in whom it is indicated. (C)

(2) Knowledge of recommended screening intervals and adherence to practice guidelines. (C)

(3) Adequate documentation of all lesions found on FS, allowing the colonoscopist to complete removal of unremoved lesions. (C)

(4) Annual performance reviews of clinicians performing FS, measuring complications, depth of insertion, and detection of polyps and cancer. (C)

(5) Identification and appropriate reaction with respect to anticoagulation and antibiotic prophylaxis. (E)

(6) Average depth of sigmoidoscope insertion stating whether level reached is maximal insertion or after straightening the endoscope. (C)

(7) Documentation in endoscopic report of depth of insertion in $\mathrm{cm}$ (100\%). (C)

(8) Patient satisfaction with the FS experience, including level of discomfort with the procedure (approximately $70 \%$ should be satisfied with the procedure). (E)

(9) Documentation of quality of bowel preparation. Goal $=100 \%$. (E)

(10) Documentation of informed consent. Goal $=100 \%$. (E)

(11) Complication rates following biopsy and polypectomy at FS. (E)

(12) Development and adherence to guidelines for the performance of FS by non-physicians, including training, supervision, and ongoing proctoring. (C)

(13) Knowledge of ASGE-SGNA guidelines on flexible endoscope reprocessing. (E)

(14) Compliance with policies for endoscope reprocessing. (E)

FS, flexible sigmoidoscopy; (C), consensus based recommendation; (E) evidence based recommendation; ASGE, American Society of Gastrointestinal Endoscopists; SGNA, Society of Gastroenterology Nurses and Associates.

was last performed on 15 July 2004 for English language articles with the MeSH terms "sigmoidoscopy" and "mass screening" published since 1980. The reference lists of identified articles were scanned for other articles of interest. Recommendations for relevant articles were also sought from the experts on the panel. Abstracts of information presented at international meetings are referenced only when necessary. Each author had an opportunity to review drafts of this position paper and had an opportunity to make meaningful revisions in the content.

\section{INTERVALS}

Endoscopists performing screening FS should know the sensitivity of FS compared with other screening tests, and the intervals at which screening $\mathrm{FS}$ is recommended. For average risk screening, FS every five years is one of several acceptable screening options. ${ }^{15-18}$ Other options include annual faecal occult blood testing (FOBT), annual FOBT combined with FS every five years, double contrast barium enema every five years, and colonoscopy every 10 years.
Advanced neoplasms or cancers may be found in the interval between screening examinations ${ }^{19} 20$ because of limited test sensitivity or rapid cancer progression. The aim of screening is to reduce the risk of dying from colorectal cancer or developing the disease. No screening strategy can eliminate this risk entirely. Any screening approach carries risks and costs and these must be balanced with the risk of missing potentially important precancerous or cancerous neoplasms. Because screening is directed at people without symptoms, avoidance of harm from screening is paramount. A 10 year interval between FS examinations is supported by two case control studies of FS screening demonstrating similar risk reduction for 10 year or longer screening intervals as more frequent intervals, including one in the rigid sigmoidoscopy era. ${ }^{4}$ Additional supporting evidence is provided by a study showing that significant neoplasms were rare five years after a negative colonoscopy. ${ }^{21}$

Differential sensitivity for FS and colonoscopy for the distal colon has never been demonstrated but the five year interval for FS screening is chosen in most guidelines because unsedated FS patients may become uncomfortable during

Table 2 Areas for future research related to performance of flexible sigmoidoscopy

(1) What is the degree of adherence to recommended intervals between FS examinations among both gastroenterologists and non-gastroenterologists?

(2) Is there a clinically meaningful difference between a 5 year interval between FS examinations and a 10 year interval?

(3) What portion of the adenoma bearing cohort can safely have a follow up colonoscopy delayed until after the age of 60 years?

(4) Would a single FS between age 50-59 years successfully stratify the population according to subsequent risk of colorectal cancer, guiding the need for subsequent screening or surveillance?

(5) What will be missed by delaying this initial examination until after the age of 60 years?

(6) How many examinations are necessary to achieve and maintain technical procedural competence?

(7) What defines a complete FS insertion, based on clinically important outcomes?

(8) What should be done when a screening FS is incomplete or suboptimal?

(9) What technical improvements could improve the ease, speed, and safety of FS?

(10) Do smaller diameter endoscopes improve FS performance or patient satisfaction?

(11) What is the preferred bowel preparation for flexible sigmoidoscopy, balancing preparation quality, patient satisfaction, and safety?

(12) Are there differences in rates of missed cancer or advanced lesions by non-physicians compared with generalist and specialist physicians?

(13) Do patient preferences vary for physician $v$ non-physician providers of FS?

(14) To what degree do office based primary care providers performing FS adhere to endoscope reprocessing guidelines?

(15) What is the incidence of preventable transmissible infection related to FS procedures and are these events related to inadequate compliance with reprocessing guidelines?

(16) Can disposable sheath endoscopes be a feasible means of delivering flexible sigmoidoscopy in high volume with reduced risk of transmitting infection? 
the procedure, impairing thorough examination of the colonic mucosa. The typically less complete bowel preparation for FS compared with colonoscopy may also limit complete visualisation. FS examiners may have less experience interpreting colonic findings compared with specialists who usually perform colonoscopy. In situations where an experienced endoscopist performs a complete examination on a well prepared patient and comfortably achieves an adequate examination, a 10 year interval between screening flexible sigmoidoscopies may be justified, ${ }^{17}$ although more research on this issue is needed. While the incidence of clinically detected colorectal cancer during the five years after a negative screening flexible sigmoidoscopy may be low, ${ }^{20} 22$ advanced lesions may be found on repeat examination done as soon as three years after a negative initial screen. ${ }^{19}$ Many of the advanced lesions detected after an apparently negative FS will be in regions of the colon beyond the reach of the FS endoscope; a fraction will also be found in the distal colon.

\section{DOCUMENTATION}

The performance of FS requires that findings must be documented adequately enough to allow other clinicians to provide appropriate follow up for the patient. The size (in $\mathrm{mm})$, number, and location of any lesions found on FS, especially lesions that are incompletely removed, must be recorded in the procedure report (table 3), and in any communication between the sigmoidoscopist and the colonoscopist. Other necessary items include depth of insertion (in $\mathrm{cm}$, and ideally with a straightened endoscope) with estimation of the colonic segment. Additional findings such as diverticulosis and haemorrhoids, whether a retroflex view has been obtained, and qualitative estimation of the preparation should also be recorded. Examination of the anal canal and the perianal area should also be made and comments included if abnormal.

\section{REFERRAL FOR COLONOSCOPY}

The glandular structure of adenomas can be characterised as either tubular or villous. If more than $80 \%$ of the polyp contains tubular elements, the polyp is classified as a tubular adenoma (TA). If more than $80 \%$ of the polyp contains villous elements, it is classified as a villous adenoma. If neither tubular nor villous elements exceed $80 \%$, then the polyp is classified as a tubulovillous adenoma. Most adenomas are TAs.

In most studies, an "advanced adenoma" (AA) is defined as an adenoma with high grade dysplasia, villous elements, or $\geqslant 1 \mathrm{~cm}$ in size (as estimated using an open biopsy forceps). As patients with one or two TAs smaller than $1 \mathrm{~cm}$ are clearly not at increased risk of subsequent colorectal cancer, ${ }^{23}$ the focus of screening and surveillance has shifted progressively towards the AA and cancer, and away from the finding of a single TA. AAs have a greater risk of transforming into cancer, and patients with resected AAs have a greater risk of having recurrent AAs and cancers. ${ }^{23} 24$ Furthermore, advanced histology in adenomas found at FS predicts an increased likelihood of finding advanced proximal colonic neoplasia in the proximal colon. ${ }^{25-29}$

The decision to perform colonoscopy based on the findings at FS remains an area of debate, which is complicated by the fact that biopsy is not universally available at FS. ${ }^{30}$ Patients with only hyperplastic polyps in the distal colon should be considered to have had a normal examination. Patients are at increased risk of advanced proximal neoplasia or subsequent development of colorectal cancer if multiple $(\geqslant 3)$ TAs are found, if the adenomas are advanced, or if a positive family history is present. ${ }^{23}{ }^{27}$ Age 65 years or older is also associated with increased risk for advanced proximal neoplasia. ${ }^{27} 3132$ Additional screening with FOBT, barium radiography, or colonoscopy may be justified in older patients, as an alternative to FS. If a large polyp $(>1 \mathrm{~cm})$ is found at flexible sigmoidoscopy, colonoscopy is generally indicated to complete removal of this lesion and to exclude synchronous proximal neoplasia. The majority of polyps $1 \mathrm{~cm}$ or larger in size are adenomas, and it is not necessary to perform biopsies to determine whether colonoscopy is indicated.

The risk of proximal AAs and cancer among patients with 1 or 2 small $(<1 \mathrm{~cm})$ distal adenomas found on flexible sigmoidoscopy is less than $10 \% .{ }^{25-29}{ }^{33-35}$ This risk may not be higher than that of the general population but may still be high enough to warrant colonoscopy, depending on patient preferences, age, comorbidity, and resource availability.

\section{TRAINING IN FS}

Cognitive and technical skills are both required for screening FS. Trainees develop skills at variable rates due to differences in manual dexterity, interpretative skills, clinical judgment, and quality of instruction. Prospective studies are limited as to the most appropriate method to train clinicians to perform screening FS. ${ }^{36}$ Clinicians of multiple backgrounds have been trained in FS, including primary care physicians, registered nurses, nurse practitioners, and physician assistants.

Training should begin with instruction in basic anatomy and typical pathological findings in the distal colon and rectum. Didactic study can include review of textbooks or compact disks on the performance of $\mathrm{FS}^{37}$ A formalised training programme may allow determination of competency in the performance of $\mathrm{FS}^{38}$ Understanding the indications and contraindications for FS are part of the cognitive process. Initial hands-on training begins with time spent becoming familiar with the technical aspects of handling the sigmoidoscope by practising on a plastic model. In an endoscopy unit, the trainee spends time observing both colonoscopic and sigmoidoscopic examinations to become familiar with the basic anatomy of the colon and the appearance of normal and abnormal findings. Hands-on experience during actual

\begin{tabular}{|c|c|}
\hline Element & Examples and comments \\
\hline Informed consent & $\begin{array}{l}\text { The procedure, its indications, risks, benefits and alternatives were } \\
\text { explained to the patient, who had an opportunity to ask questions, and } \\
\text { indicated a desire to proceed. }\end{array}$ \\
\hline $\begin{array}{l}\text { Preparation quality } \\
\text { Size, number and location of lesions }\end{array}$ & $\begin{array}{l}\text { Good, fair, poor } \\
\text { Size: in mm diameter; location in } \mathrm{cm} \text { from the anal verge and in estimated } \\
\text { colon segment }\end{array}$ \\
\hline $\begin{array}{l}\text { Presence of other abnormalities } \\
\text { Performance of retroflexion }\end{array}$ & $\begin{array}{l}\text { Diverticulosis, haemorrhoids, inflammatory findings } \\
\text { May not be feasible or safe in all patients }\end{array}$ \\
\hline Disposition & $\begin{array}{l}\text { Barium enema or colonoscopy to be done soon, repeat sigmoidoscopy in } \\
5 \text { or } 10 \text { years, further follow up based on recommendations of primary } \\
\text { care provider, clinicians identified as providing follow up care }\end{array}$ \\
\hline
\end{tabular}


procedures begins by first withdrawing the instrument under direct supervision. Once the trainee can perform the withdrawal successfully, he or she can begin to advance the scope. Training then progresses through several stages along a continuum of graded responsibility and reduced supervision. Cold biopsy techniques should be part of the training process. ${ }^{39}$

Short courses in FS are adjuncts or starting points in the training process and do not substitute for mentored training by an experienced proficient endoscopist. ${ }^{40}$ Computer simulation of FS is available and a recent study demonstrated that a virtual reality sigmoidoscopy training system was a valid discriminator of FS experience. ${ }^{41}$ However, virtual reality simulators are not a substitute for traditional bedside teaching. ${ }^{42}$

A minimum of 15-25 supervised procedures was recommended in studies performed in the $1980 \mathrm{~s},{ }^{43}{ }^{44}$ but in reality more examinations may be needed. The ASGE position paper on FS recommended 25 supervised procedures before competency with the $60 \mathrm{~cm}$ instrument is assessed. ${ }^{9}$ The Society of Gastrointestinal Nurses and Associates (SGNA) as well as the Society of American Gastrointestinal Endoscopic Surgeons also recommend 25 supervised procedures. ${ }^{45} 46$ Others have suggested that 50-100 supervised procedures are needed to effectively train clinicians with no previous endoscopic skills. ${ }^{47}{ }^{48}$ Furthermore, a minimum number of FS should be done yearly to maintain proficiency.

\section{ANTIBIOTIC PROPHYLAXIS AND ANTICOAGULATION}

FS with or without biopsy or polypectomy is associated with a low risk of bacteraemia. However, patients may be considered on a case by case basis for antibiotic prophylaxis if they have high risk conditions for endocarditis (for example, prosthetic heart valve or history of endocarditis) and during the first year after placement of a synthetic vascular graft. Antibiotics are not recommended prior to FS to prevent infection of prosthetic joints or orthopaedic prostheses. The issue of antibiotic prophylaxis is discussed in detail elsewhere. ${ }^{49} 50$

Therapeutic anticoagulation with warfarin is associated with an increased risk of bleeding after polypectomy but not after mucosal biopsy. ${ }^{51}$ Management of anticoagulation before and after the procedure depends on the risk of thromboembolism and is discussed in detail elsewhere. ${ }^{51}$ Anticoagulants, antiplatelet agents, or non-steroidal antiinflammatory medications do not need to be stopped prior to FS, as long as polypectomies are deferred to colonoscopy.

\section{FS INSERTION}

The goal of FS is to examine as much of the distal colon as possible based on the limits of FS endoscope length (usually $60-70 \mathrm{~cm}$ ) or to the limits of patient tolerance. In general, high levels of patient satisfaction can be achieved with FS screening, ${ }^{52}$ and the use of carbon dioxide instead of air for colon insufflation is associated with reduced post procedural discomfort and reduced risk for cautery related complications. Insertion depths in women are less than in men, ${ }^{53-55}$ possibly due to anatomical differences between genders. The use of a thinner diameter upper endoscope to perform FS may be better tolerated than standard sigmoidoscopes. ${ }^{56}$ Prior abdominal surgery is also associated with reduced depth of insertion, ${ }^{53}$ and prior history of hysterectomy is associated with reduced polyp detection at screening FS. ${ }^{57}$ Patients should not be subjected to excessive discomfort in order to achieve a predefined level of adequate insertion. Anatomical factors, preparation quality, or variations in patient tolerance all may limit insertion depth. The definition of an adequately inserted screening FS is subjective and not currently defined. In the screening setting, the decision to perform colonoscopy or other tests after an incomplete FS should be individualised, based on degree of risk for colorectal cancer, the limiting factor (preparation quality $v$ anatomical barriers) patient preferences, and available resources.

Localising the depth of FS insertion by anatomical segment is unreliable. The rectum is usually traversed by the distal $10-20 \mathrm{~cm}$ of the FS endoscope. The procedure report should document the depth of insertion of the FS endoscope in centimetres from the anal verge, ideally with a straightened endoscope. Smaller diameter "paediatric" FS endoscopes are available that are more flexible than standard diameter scopes. It is not clear that these differences make a clinically important difference in patient satisfaction or in depth of insertion. ${ }^{58}$

\section{ADENOMA DETECTION}

Endoscopy is not perfect. Miss rates for small adenomas on colonoscopy may be substantial, and occasionally polyps $\geqslant 1 \mathrm{~cm}$ are missed. ${ }^{59}{ }^{60}$ Adenoma detection rates may vary widely between different examiners, within similar patient populations. ${ }^{6162}$ Adequate colonic distension, adequate suctioning and cleaning, and adequate time spent examining the colonic mucosa all correlate with higher detection rates. ${ }^{61-63}$ The prevalence of adenomas in a given population will vary according to the age and sex of those being screened. Adenoma detection may be a useful surrogate marker for the quality of an examination but has not yet been proven to correlate directly with differences in colorectal cancer incidence or mortality in a FS screening programme. ${ }^{64}$ The use of dye spray to enhance detection of flat and diminutive lesions in the distal colon tends to lead to increased detection of smaller and non-neoplastic lesions, and the clinical benefit may be minimal..$^{65}$

\section{PREPARATION}

The FS procedure report should document the quality of preparation and any impairment in the endoscopist's confidence attributable to preparation, but there is no standardised system for describing bowel preparation. An adequate examination is one that allows confidence that mass lesions other than small $(\leqslant 5 \mathrm{~mm})$ polyps were generally not obscured by the preparation. Recommended intervals for screening and surveillance assume adequate preparation.

Most FS units use sodium phosphate enemas to prepare patients for FS. The use of oral agents with an enema preparation has demonstrated improved preparation quality when the enemas are combined with an oral laxative, such as magnesium citrate or oral sodium phosphate. ${ }^{67-70}$ Caution should be exercised to avoid electrolyte disturbances and dehydration with the use of oral osmotic agents, particularly in the elderly and in those taking diuretics. ${ }^{71}$ When preparation quality is suboptimal, it is incumbent upon the endoscopist to make adequate arrangements in the follow up of the patient. Options include repeating the examination with a modified preparation, shortening the interval between screening examinations, or pursuing an alternative screening strategy, such as FOBT or double contrast barium enema.

\section{COMPLICATIONS AND INFORMED CONSENT}

Perforation related to FS occurs rarely. Recent reports suggest that perforations occur in 1 in $25000-50000$ FS examinations. ${ }^{12} 5472$ The expected rate of major post polypectomy bleeding is $<1 \% .{ }^{73-75}$ The risk of major bleeding from mucosal biopsy is near zero, even among patients who are therapeutically anticoagulated. ${ }^{51}$ Perforation may result from either mechanical rupture of the colon from instrument passage, barotrauma, or from polypectomy or other therapeutic procedures. The most important rule to avoid mechanical perforation is not to push forcibly against the sensation of 
fixed resistance. Forceful perforation is less likely in FS compared with colonoscopy as FS patients are usually not sedated, and less force is applied to colonic loops by the endoscope shaft.

It is desirable for individuals performing FS to be proficient in performing endoscopic biopsies. The risk of explosion associated with the use of electrocautery, while small, is real, and an important reason to avoid the use of hot biopsy forceps or monopolar electrocautery snares in air insufflated patients. ${ }^{76-80}$ Polyps larger than $2 \mathrm{~mm}$ or smaller than $7 \mathrm{~mm}$ can be removed safely with a cold snare. Smaller flat polyps, not easily grasped with a snare, can be removed piecemeal with cold biopsy forceps. The use of carbon dioxide insufflation instead of air eliminates the risk of combustion. ${ }^{81} 82$ Cold snaring is particularly attractive for polyps $<7 \mathrm{~mm}$ in size, based on endoscopist discretion, as anecdotal data suggest no risk of perforation and a very low risk of post polypectomy bleeding. ${ }^{83}$ Thus cold snaring may be an effective way to remove small polyps and nearly eliminate associated complications.

It is acceptable to obtain consent for FS on the day of the procedure, preferably prior to entering the examination room. Informed consent for FS should focus on three possible adverse outcomes.

- Perforation and the probable need for surgical repair if this occurs.

- Missing a significant neoplasm (including, but not limited to, lesions beyond the reach of the sigmoidoscope).

- Post polypectomy and post biopsy haemorrhage.

\section{NURSE AND PHYSICIAN ASSISTANT ENDOSCOPISTS}

A large and consistent evidence base supports the use of nonphysicians for sigmoidoscopy. In several studies, average depth of insertion, polyp yield, complications, procedure time, and patient satisfaction were all similar for non-physicians, non-gastroenterologist physicians, and gastroenterologists. ${ }^{545-88}$ In settings where fee for service reimbursement is not an issue, such as the Department of Veterans' Affairs Medical Centers and prepaid medical groups, the use of non-physicians has become commonplace.

\section{FLEXIBLE SIGMOIDOSCOPE REPROCESSING}

Guidelines for endoscope reprocessing have been reviewed in detail elsewhere, ${ }^{89}$ and have recently been updated. ${ }^{29}$ The ASGE-SGNA guidelines recommend manual precleaning of endoscopes, with a 20 minute submersion in a $2.4 \%$ glutaraldehyde solution. ${ }^{90}$ A recent highly publicised series describing patient to patient transmission of hepatitis $C$ via colonoscopy ${ }^{91}$ has raised public awareness and concern. Other infections related to gastrointestinal endoscopy include salmonella, pseudomonas, and hepatitis B. ${ }^{92}$ Based on survey data, it is apparent that even gastroenterology specialists may not be uniformly aware of disinfection practices. ${ }^{93}$ The quality of endoscopic reprocessing can vary and, in general, manual reprocessing is inferior to the use of automatic endoscope reprocessing machines. ${ }^{94}$ Bacterial contaminants can be detected in samples obtained from endoscopes cleaned according to current guidelines. ${ }^{95}$ One possible solution for clinicians performing FS without access to disinfection facilities is the use of the disposable sheath flexible sigmoidoscope. ${ }^{96-98}$ This device has the advantage of also limiting staff and patient exposure to hazardous chemicals, such as glutaraldehyde. This endoscope is only available as a fibreoptic instrument, and is technically more difficult to use than video flexible endoscopes.

\section{CONCLUSIONS}

FS remains an important tool for screening and prevention of colorectal cancer. It can be delivered in high volume, by a variety of examiners, safely, and with high patient satisfaction. The effectiveness of FS depends on the quality of examination. We anticipate that a constructive process of continuous quality improvement that educates endoscopists in optimal technique, procedure documentation, specimen acquisition, and endoscope reprocessing could improve patient outcomes. The recommendations and rationale for continuous quality improvement made in this document are evidence based where possible and consensus based where no evidence exists. The Task Force recommends that all of the targets recommended above be periodically reviewed in continuous quality improvement programmes. Findings of deficient performance can be used to educate endoscopists, and additional monitoring can be undertaken to document improvement in performance. Furthermore, we recommend that both academic and community based programmes report the results of their reviews of adherence to these continuous quality improvement measures in the peer reviewed medical literature.

\section{Authors' affiliations}

T R Levin, Department of Gastroenterology, Kaiser Permanente Medical Center, CA, USA, and Kaiser Permanente Division of Research, Oakland, CA, USA

F A Farraye, Section of Gastroenterology, Boston Medical Center, Boston University School of Medicine, Boston, MA, USA

R E Schoen, Department of Medicine/Gastroenterology, University of Pittsburgh Medical Center, Pittsburgh, PA, USA

G Hoff, Institute of Population-based Cancer Research, Oslo, Norway

W Atkin, Cancer Research UK Colorectal Cancer Unit, St Mark's Hospital, Harrow, UK

J H Bond, Department of Medicine/Gastroenterology, Minneapolis VA Medical Center, University of Minnesota, Minneapolis, MN, USA

S Winawer, Department of Medicine/Gastroenterology, Memorial Sloan-Kettering Cancer Center, New York, NY, USA

R W Burt, Department of Medicine/Gastroenterology, Huntsman Cancer Institute at the University of Utah, Salt Lake City, UT, USA

D A Johnson, Department of Medicine/Gastroenterology, Eastern Virginia School of Medicine, Norfolk, VA, USA

L M Kirk, Department of Internal Medicine, University of Texas

Southwestern Medical Center at Dallas, Dallas, TX, USA

S C Litin, Department of Internal Medicine, Mayo Clinic, Rochester, MN, USA

D K Rex, Department of Medicine/Gastroenterology, Indiana University Medical Center, Indianapolis, IN, USA

Conflict of interest: None declared.

\section{REFERENCES}

1 Jemal A, Thomas A, Murray T, et al. Cancer statistics, 2002. CA Cancer J Clin 2002;52:23-47.

2 Kavanagh AM, Giovannucci EL, Fuchs CS, et al. Screening endoscopy and risk of colorectal cancer in United States men. Cancer Causes Control 1998;9:455-62.

3 Slattery ML, Edwards SL, Ma KN, et al. Colon cancer screening, lifestyle, and risk of colon cancer. Cancer Causes Control 2000;11:555-63.

4 Selby JV, Friedman GD, Quesenberry CP, et al. A case-control study of screening sigmoidoscopy and mortality from colorectal cancer. N Engl J Med 1992;326:653-7.

5 Muller AD, Sonnenberg A. Protection by endoscopy against death from colorectal cancer. Arch Intern Med 1995;155:1741-8.

6 Newcomb PA, Norfleet RG, Storer BE, et al. Screening sigmoidoscopy and colorectal cancer mortality. J Natl Cancer Inst 1992;84:1572-5.

7 Newcomb PA, Storer BE, Morimoto LM, et al. Long-term efficacy of sigmoidoscopy in the reduction of colorectal cancer incidence. J Natl Cancer Inst 2003;95:622-5.

8 Thiis-Evensen E, Hoff GS, Sauar J, et al. Population-based surveillance by colonoscopy: effect on the incidence of colorectal cancer. Telemark Polyp Study I. Scand J Gastroenterol 1999;34:414-20.

9 Gross GWW, Bozymski EM, Brown RD, et al. Guidelines for training nonspecialists in screening flexible sigmoidoscopy. Gastrointest Endosc 2000;51:783-5.

10 Gohagan JK, Prorok PC, Hayes RB, et al. The Prostate, Lung, Colorectal and Ovarian (PLCO) Cancer Screening Trial of the National Cancer Institute: 
history, organization, and status. Control Clin Trials 2000;21(suppl 6): 251-72S

11 Prorok PC, Andriole GL, Bresalier RS, et al. Design of the Prostate, Lung, Colorectal and Ovarian (PLCO) Cancer Screening Trial. Control Clin Trials 2000;21(suppl 6):273-309S

12 UK Flexible Sigmoidoscopy Screening Trial Investigators. Single flexible sigmoidoscopy screening to prevent colorectal cancer: baseline findings of a UK multicentre randomised trial. Lancet 2002;359:1291-300.

13 Bretthaver M, Gondal G, Larsen K, et al. Design, organization and management of a controlled population screening study for detection of colorectal neoplasia: attendance rates in the NORCCAP study (Norwegian Colorectal Cancer Prevention). Scand J Gastroenterol 2002;37:568-73.

14 Gondal G, Grotmol T, Hofstad B, et al. The Norwegian Colorectal Cancer Prevention (NORCCAP) screening study: baseline findings and implementations for clinical work-up in age groups 50-64 years. Scand J Gastroenterol 2003;38:635-42.

15 Smith RA, VonEschenbach AC, Wender R, et al. American Cancer Society guidelines for the early detection of cancer: Update of early detection guidelines for prostate, colorectal, and endometrial cancers and Update 2001: Testing for early lung cancer detection. CA Cancer J Clin 2001;51:38-75.

16 Rex DK, Johnson DA, Lieberman DA, et al. Colorectal cancer prevention 2000: screening recommendations of the American College of Gastroenterology. American College of Gastroenterology. Am J Gastroenterol 2000;95:868-77.

17 Winawer S, Fletcher R, Rex D, et al. Colorectal cancer screening and surveillance: Clinical guidelines and rationale-Update based on new evidence. Gastroenterology 2003;124:544-60.

18 US Preventive Services Task Force. Screening for colorectal cancer: recommendation and rationale. Ann Intern Med 2002;137:129-31.

19 Schoen RE, Pinsky PF, Weissfeld JL, et al. Results of repeat sigmoidoscopy 3 years after a negative examination. JAMA 2003;290:41-8.

20 Doria-Rose VP, Levin TR, Selby JV, et al. The incidence of colorectal cancer following a negative screening sigmoidoscopy: implications for screening interval. Gastroenterology 2004; 127:714-22.

21 Rex DK, Cummings OW, Helper DJ, et al. 5-year incidence of adenomas after negative colonoscopy in asymptomatic average-risk persons. Gastroenterology 1996;111:1178-81.

22 Platell CFE, Philpott G, Olynyk JK. Flexible sigmoidoscopy screening for colorectal neoplasia in average-risk people: evaluation of a five year screening interval. Med J Aust 2002;176:371-3.

23 Atkin WS, Morson BC, Cuzick J. Long-term risk of colorectal cancer after excision of rectosigmoid adenomas. N Engl J Med 1992;326:658-62.

24 Zauber AG, Winawer SJ. Initial management and follow-up surveillance of patients with colorectal adenomas. Gastroenterol Clin North Am 1997;26:85-101

25 Lieberman DA, Weiss DG, Bond JH, et al. Use of colonoscopy to screen asymptomatic adults for colorectal cancer. Veterans Affairs Cooperative Study Group 380. N Engl J Med 2000;343:162-8

26 Imperiale TF, Wagner DR, Lin CY, et al. Risk of advanced proximal neoplasms in asymptomatic adults according to the distal colorectal findings. NEngl J Med 2000;343:169-74.

27 Levin TR, Palitz A, Grossman S, et al. Predicting advanced proximal colonic neoplasia with screening sigmoidoscopy. JAMA 1999;281:1611-17.

28 Lewis JD, $\mathrm{Ng} \mathrm{K}$, Hung KE, et al. Detection of proximal adenomatous polyps with screening sigmoidoscopy: a systematic review and meta-analysis of screening colonoscopy. Arch Intern Med 2003;163:413-20.

29 Pinsky PF, Schoen RE, Weissfeld JL, et al. Predictors of advanced proximal neoplasia in persons with abnormal screening flexible sigmoidoscopy. Clin Gastroenterol Hepatol 2003;1:103-10.

30 Farraye FA, Wallace M. Clinical significance of small polyps found during screening with flexible sigmoidoscopy. Gastrointest Endosc 2002;12:41-51.

31 Slattery ML, Friedman GD, Potter JD, et al. A description of age, sex, and site distributions of colon carcinoma in three geographic areas. Cancer 1996;78:1666-70.

32 Cooper GS, Yuan Z, Landefeld CS, et al. A national population-based study of incidence of colorectal cancer and age. Implications for screening in older Americans. Cancer 1995;75:775-81.

33 Wallace MB, Kemp JA, Trnka YM, et al. Is colonoscopy indicated for small adenomas found by screening flexible sigmoidoscopy? Ann Intern Med 1998; 129:273-8.

34 Read TE, Read JD, Butterly LF. Importance of adenomas $5 \mathrm{~mm}$ or less in diameter that are detected by sigmoidoscopy. N Engl J Med 1997;336:8-12.

35 Schoen R, Corle D, Cranston L, et al. Is colonoscopy needed for the nonadvanced adenoma found on sigmoidoscopy? Gastroenterology 1998; 115:533-41.

36 Ashley OS, Nadel M, Ransohoff DF. Achieving quality in flexible sigmoidoscopy screening for colorectal cancer. Am J Med 2001;11 1:643-53.

37 Rex DK, Lewis BS. Flexible sigmoidoscopy. Cambridge, MA: Blackwell Science, Inc, 1996.

38 Proctor DD, Price J, Dunn KA, et al. Prospective evaluation of a teaching model to determine competency in performing flexible sigmoidoscopies. Am J Gastroenterol 1998;93:1217-21.

39 Horton K, Reffel A, Rosen K, et al. Training of nurse practitioners and physician assistants to perform screening flexible sigmoidoscopy. J Am Acad Nurse Pract 2001; 13:455-9.

40 American Society for Gastrointestinal Endoscopy guidelines for clinical application. Statement on role of short courses in endoscopic training. American Society for Gastrointestinal Endoscopy. Gastrointest Endosc 1999;50:913-14.
41 Datta VMM, Mackay S, Darzi A. The PreOp flexible sigmoidoscopy trainer. Validation and early evaluation of a virtual reality based system. Surg Endosc 2002; 16:1459-63.

42 Gerson LB, Van Dam J. A prospective randomized trial comparing a virtual reality simulator to bedside teaching for training in sigmoidoscopy. Endoscopy 2003;35:569-75

43 Hawes R, Lehman GA, Hast J, et al. Training resident physicians in fiberoptic sigmoidoscopy. How many supervised examinations are required to achieve competence? Am J Med 1986:80:465-70.

44 Health and Public Policy Committee. Clinical competence in the use of flexible sigmoidoscopy for screening purposes. Ann Intern Med 1987; 107:589-91.

45 Wexner SD, Eisen GM, Simmang C. Principles of privileging and credentialing for endoscopy and colonoscopy. Surg Endosc 2002;16:367-9.

46 Society of Gastroenterology Nurses and Associates. Performance of flexible sigmoidoscopy by registered nurses for the purpose of colorectal cancer creening. SGNA guideline. Society of Gastroenterology Nurses and Associates. Gastroenterol Nurs 2000;23:83-5.

47 Wallace MBKJ, Meyer F, Horton K, et al. Screening for colorectal cancer with flexible sigmoidoscopy by nonphysician endoscopists. Am J Med 1999:107:214-18.

48 Levin T. Flexible sigmoidoscopy for colorectal cancer screening: valid approach or short-sighted? Gastroenterol Clin North Am 2002;31:1015-29.

49 American Society for Gastrointestinal Endoscopy. Antibiotic prophylaxis for gastrointestinal endoscopy. Gastrointest Endosc 1995:42:630-5.

50 Hirota W, Petersen K, Baron T, et al. Guidelines for antibiotic prophylaxis for Gl endoscopy. Gastrointest Endosc 2003;58:475-82.

51 American Society for Gastrointestinal Endoscopy. Guideline on the management of anticoagulation and antiplatelet therapy for endoscopic procedures. Gastrointest Endosc 1998;48:672-5.

52 Schoen RE, Weissfeld JL, Bowen NJ, et al. Patient satisfaction with screening flexible sigmoidoscopy. Arch Intern Med 2000;160:1790-6

53 Stewart BT, Keck JO, Duncan AV, et al. Difficult or incomplete flexible sigmoidoscopy: implications for a screening programme. Aust N Z J Surg 1999;69:19-21

54 Levin TR, Conell C, Shapiro JA, et al. Complications of screening flexible sigmoidoscopy. Gastroenterology 2002;123:1786-92.

55 Eloubeidi MA, Wallace MB, Desmond R, et al. Female gender and other factors predictive of a limited screening flexible sigmoidoscopy examination for colorectal cancer. Am J Gastroenterol 2003;98:1634-9.

56 Farraye FA, Horton K, Hersey H, et al. Screening flexible sigmoidoscopy using an upper endoscope is better tolerated by women. Am J Gastroenterol 2004;99: 1074-80.

57 Adams C, Cardwell C, Cook C, et al. Effect of hysterectomy status on polyp detection rates at screening flexible sigmoidoscopy. Gastrointest Endosc 2003;57:848-53

58 Marshall J, Perez R, Madsen R. Usefulness of a pediatric colonoscope for routine colonoscopy in women who have undergone hysterectomy. Gastrointest Endosc 2002;55:838-41.

59 Rex DK, Cutler CS, Lemmel GT, et al. Colonoscopic miss rates of adenomas determined by back to back colonoscopies. Gastroenterology 1997; 112:243-8

60 Hixson LS, Fennerty MB, Sampliner RE, et al. Prospective study of the frequency and size distribution of polyps missed by colonoscopy. J Natl Cancer Inst 1990;82:1769-72.

61 Bretthaver M, Skovlund E, Grotmol T, et al. Inter-endoscopist variation in polyp and neoplasia pick-up rates in flexible sigmoidoscopy screening for colorectal cancer. Scand J Gastroenterol 2003;38:1268-74.

62 Atkin W, Rogers $\mathrm{P}$, Cardwell C, et al. Wide variation in adenoma detection rates at screening flexible sigmoidoscopy. Gastroenterology 2004; 126:1247-56.

63 Rex DK. Colonoscopic withdrawal technique is associated with adenoma miss rates. Gastrointest Endosc 2001;51:33-6.

64 Zauber AG. Quality control for flexible sigmoidoscopy: which polyps count? Gastroenterology 2004;126:1474-7.

65 Painter JE, O'Dwyer ST, Watson AJ, et al. The routine use of chromoscopy is of no benefit in flexible sigmoidoscopy screening for colorectal cancer. Gut 1999;44:A99.

66 Brooker JC, Saunders BP, Shah SG, et al. Total colonic dye-spray increases the detection of diminutive adenomas during routine colonoscopy: a randomized controlled trial. Gastrointest Endosc 2002;56:333-8.

67 Bini EJ, Unger JS, Rieber JM, et al. Prospective, randomized, single-blind comparison of two preparations for screening flexible sigmoidoscopy. Gastrointest Endosc 2000;52:218-22.

68 Osgard E, Jackson JL, Strong J. A randomized trial comparing three methods of bowel preparation for flexible sigmoidoscopy. Am J Gastroenterol 1998;93:1126-30.

69 Fincher RK, Osgard EM, Jackson JL, et al. A comparison of bowe preparations for flexible sigmoidoscopy: oral magnesium citrate combined with oral bisacodyl, one hypertonic phosphate enema, or two hypertonic phosphate enemas. Am J Gastroenterol 1999;94:2122-7.

70 Sharma VK, Chockalingham S, Clark V, et al. Randomized, controlled comparison of two forms of preparation for screening flexible sigmoidoscopy. Am J Gastroenterol 1997;92:809-11

71 Beloosesky Y, Grinblat J, Weiss A, et al. Electrolyte disorders following oral sodium phosphate administration for bowel cleansing in elderly patients. Arch Intern Med 2003;163:803-8

72 Anderson ML, Pasha TM, Leighton JA. Endoscopic perforation of the colon: lessons from a 10-year study. Am J Gastroenterol 2000;95:3418-22. 
73 Silvis SE, Nebel O, Rogers G, et al. Endoscopic complications. Results of the 1974 American Society for Gastrointestinal Endoscopy Survey. JAMA 1976;235:928-30.

74 Nivatvongs S. Complications in colonoscopic polypectomy. An experience with 1,555 polypectomies. Dis Colon Rectum 1986;29:825-30.

75 Fruhmorgen P, Demling L. Complications of diagnostic and therapeutic colonoscopy in the Federal Republic of Germany. Results of an inquiry. Endoscopy 1979;11:146-50.

76 Bisson B. Methane gas explosion during colonoscopy. Gastroenterol Nurs 1997;20:136-7.

77 Bond JH, Levitt MD. Colonic gas explosion - is a fire extinguisher necessary? Gastroenterology 1979;77:1349-50.

78 Monahan DW, Peluso FE, Goldner F. Combustible colonic gas levels during flexible sigmoidoscopy and colonoscopy. Gastrointest Endosc 1992:38:40-3.

79 Soussan E, Mathieu N, Roque I, et al. Bowel explosion with colonic perforation during argon plasma coagulation for hemorrhagic radiation-induced proctitis. Gastrointest Endosc 2003;57:412-13.

80 Taylor EW, Keighley MR. Fatal colonic explosion. Gastroenterology 1980;79:178.

81 Larsen JF, Ejstrud P, Svendsen F, et al. Systemic response in patients undergoing laparoscopic cholecystectomy using gasless or carbon dioxide pneumoperitoneum: a randomized study. J Gastrointest Surg 2002;6:582-6.

82 Bretthaver M, Hoff G, Thiis-Evensen E, et al. Carbon dioxide insufflation reduces discomfort due to flexible sigmoidoscopy in colorectal cancer screening. Scand J Gastroenterol 2002;37:1103-7.

83 Tappero G, Gaia E, De Giuli P, et al. Cold snare excision of small colorectal polyps. Gastrointest Endosc 1992;38:310-13.

84 Waye JD. New methods of polypectomy. Gastrointest Endosc Clin N Am 1997:7:413-22.

85 Palitz AM, Selby JV, Grossman S, et al. The Colon Cancer Prevention Program (CoCaP): rationale, implementation, and preliminary results. HMO Pract 1997;11:5-12.

86 Schoenfeld P, Lipscomb S, Crook J, et al. Accuracy of polyp detection by gastroenterologists and nurse endoscopists during flexible sigmoidoscopy: a randomized trial. Gastroenterology 1999;117:312-18.
87 Schoenfeld PS, Cash B, Kita J, et al. Effectiveness and patient satisfaction with screening flexible sigmoidoscopy performed by registered nurses. Gastrointest Endosc 1999;49:158-62.

88 Wallace MB, Kemp JA, Meyer F, et al. Screening for colorectal cancer with flexible sigmoidoscopy by nonphysician endoscopists. Am J Med 1999:107:214-18.

89 Walter VA, DiMarino AJ Jr. American Society for Gastrointestinal EndoscopySociety of Gastroenterology Nurses and Associates Endoscope Reprocessing Guidelines. Gastrointest Endosc Clin N Am 2000;10:265-73.

90 DiMarino AJ, Bond WW. Flexible gastrointestinal endoscopic reprocessing. Gastrointest Endosc 1996;43:522-4

91 Bronowicki JP, Venard V, Botte C, et al. Patient-to-patient transmission of hepatitis C virus during colonoscopy. N Engl J Med 1997;337:237-40.

92 Spach DH, Silverstein FE, Stamm WE. Transmission of infection by gastrointestinal endoscopy and bronchoscopy. Ann Intern Med 1993; 118:117-28.

93 Cheung RJ, Ortiz D, DiMarino AJ Jr. Gl endoscopic reprocessing practices in the United States. Gastrointest Endosc 1999;50:362-8.

94 Bader L, Blumenstock G, Birkner B, et al. [HYGEA (Hygiene in gastroenterology-endoscope reprocessing): Study on quality of reprocessing flexible endoscopes in hospitals and in the practice setting]. Z Gastroenterol 2002;40:157-70.

95 Bretthaver M, Jorgensen A, Kristiansen B, et al. Quality control in colorectal cancer screening: Systematic microbiological investigation of endoscopes used in the NORCCAP (Norwegian Colorectal Cancer Prevention) trial. BMC Gastroenterol 2003;3:15.

96 Rothstein RI, Littenberg B. Disposable, sheathed, flexible sigmoidoscopy: a prospective, multicenter, randomized trial. The Disposable Endoscope Study Group. Gastrointest Endosc 1995:41:566-72.

97 Bretthaver M, Hoff G, Thiis-Evensen E, et al. Use of a disposable sheath system for flexible sigmoidoscopy in decentralized colorectal cancer screening. Endoscopy 2002;34:814-18.

98 Schroy PC III, Wilson S, Afdahl N. Feasibility of high-volume screening sigmoidoscopy using a flexible fiberoptic endoscope and a disposable sheath system. Am J Gastroenterol 1996;91:1331-7.

\section{EDITOR'S QUIZ: GI SNAPSHOT}

\section{An upper abdominal swelling causing nausea and vomiting}

\section{Clinical presentation}

A 75 year old woman was admitted to Elche University General Hospital for further evaluation of nausea and vomiting related to meals for one month. She had previously been well with no history of liver disease, dysphagia, or peptic ulcer. On routine physical examination an abdominal mass was discovered in the right upper quadrant and epigastrium. Results of laboratory studies and liver function tests were normal. Also, she had never been abroad and had no contact with livestock. Upper endoscopy showed extrinsic compression of the gastric lesser curve. A helical computed tomography scan was therefore done.

\section{Question}

What does this investigation show (fig 1)?

See page 842 for answer

This case is submitted by:

I Oliver, D Costa, J Lacueva, R Calpeno Department of Pathology and Surgery, Elche University General Hospital, Elche (Alicante), Spain

Correspondence to: Dr I Oliver, Department of Pathology and Surgery, Elche University General Hospital, Camí de IAlmazara, \# 11, 03202 Elche

(Alicante), Spain; israel.oliver@umh.es

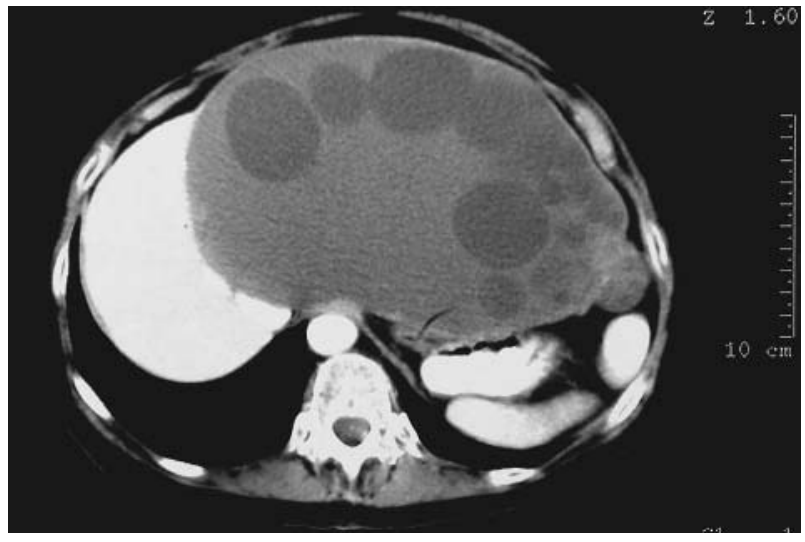

Figure 1 Helical computed tomography scan. 